\title{
Electro-oxidation of diclofenac at boron doped diamond: Kinetics and mechanism
}

\author{
Xu Zhao, Yining Hou, Huijuan Liu, Zhimin Qiang, Jiuhui Qu* \\ State Key Laboratory of Environmental Aquatic Chemistry, Research Center for Eco-Environmental Sciences, Chinese Academy of Sciences, \\ Beijing, 100085, PR China
}

\section{A R T I C L E I N F O}

\section{Article history:}

Received 13 November 2008

Received in revised form 12 February 2009

Accepted 20 February 2009

Available online 3 March 2009

\section{Keywords:}

Anti-inflammatory drugs

Diclofenac

Diamond electrode

Anode oxidation

Degradation mechanism

\begin{abstract}
A B S T R A C T
Diclofenac is a common anti-inflammatory drug. Its electrochemical degradation at boron doped diamond electrode was investigated in aqueous solution. The degradation kinetics and the intermediate products were studied. Results showed that electro-oxidation was effective in inducing the degradation of diclofenac with $30 \mathrm{mg} / \mathrm{L}$ initial concentration, ensuring a mineralization degree of $72 \%$ after a $4 \mathrm{~h}$ treatment with the applied bias potential of $4.0 \mathrm{~V}$. The effects of applied bias potential and addition of $\mathrm{NaCl}$ on diclofenac degradation were investigated. Different degradation mechanisms of diclofenac were involved at various applied bias potentials. With the addition of $\mathrm{NaCl}$, some chlorination intermediates including dichlorodiclofenac were identified, which lead to the total organic carbon increase compared with the electrolysis process without $\mathrm{NaCl}$ addition at the reaction initial period. The main intermediates including 2,6-dichlorobenzenamine, 2,5-dihydroxybenzyl alcohol, and benzoic acid are identified at the time of 2 h. 1-(2,6-Dichlorocyclohexa-2,4-dienyl)indolin-2-one were also identified. These intermediates disappeared gradually with the extension of reaction time. Small molecular acids were identified finally. Based on these results, a degradation pathway of diclofenac was proposed.
\end{abstract}

(c) 2009 Elsevier Ltd. All rights reserved.

\section{Introduction}

In recent years, pharmaceutical drugs have emerged as a novel class of water contaminants. Public and scientific concern is increasing steadily because of their potential impact on human health and the environment even at trace levels $[1,2]$. These drugs are specifically designed to elicit a biological response. Thus, it has been suggested that some drugs can inflict biological harm even at trace concentrations, with possible synergistic effects. Many pharmaceutical compounds are not effectively removed by conventional wastewater treatment processes, thus passing the compounds to surface waters that receive wastewater effluent $[3,4]$.

Physical and chemical remediation technologies such as filtration, adsorption, coagulation-flocculation, and flotation have been used to remove some pharmaceutical compounds [5]. On the other hand, advanced oxidation processes have been largely investigated for their degradation [6-11]. Recently, anodic oxidation with electronically conductive diamond anode is a new advanced oxidation process with many advantages as compared to other known chemical and photochemical processes [12,13]. A large quantity of hydroxyl radicals can be produced from water electrolysis at diamond surfaces. And, the diamond surface does not interact with these radicals, and, as a consequence, these radicals can only couple

\footnotetext{
* Corresponding author. Tel.: +86 10 62849151; fax: +861062923558.

E-mail address: jhqu@mail.rcees.ac.cn (J. Qu).
}

to form oxygen or oxidize the contaminants in the aqueous solution. It has been shown that the electrochemical oxidation with BDD anodes achieves a very high current efficiency as compared to other electrochemical treatments, and very high conversions of the organic carbon into carbon dioxide [14-16].

Diclofenac is a popular non-steroidal anti-inflammatory drug widely used to treat inflammatory and painful diseases of rheumatic and non-rheumatic origin. It has been detected in many municipal sewage treatment plant effluents [17]. Some studies indicated that diclofenac can induce some adverse effects on aquatic life $[18,19]$. And, in combination with other pharmaceuticals present in water samples, the toxic effect can be considerably increased [20]. Recently, removal of diclofenac from polluted and drinking water by AOPs has been reported $[4,21,22]$. But, only photo-Fenton treatment achieved total mineralization [22]. And, electrochemical degradation of diclofenac has not been reported. Its molecular structure is shown below.<smiles>O=C(O)CC1=CC=CCC1Nc1c(Cl)cccc1Cl</smiles>

Diclofenac 

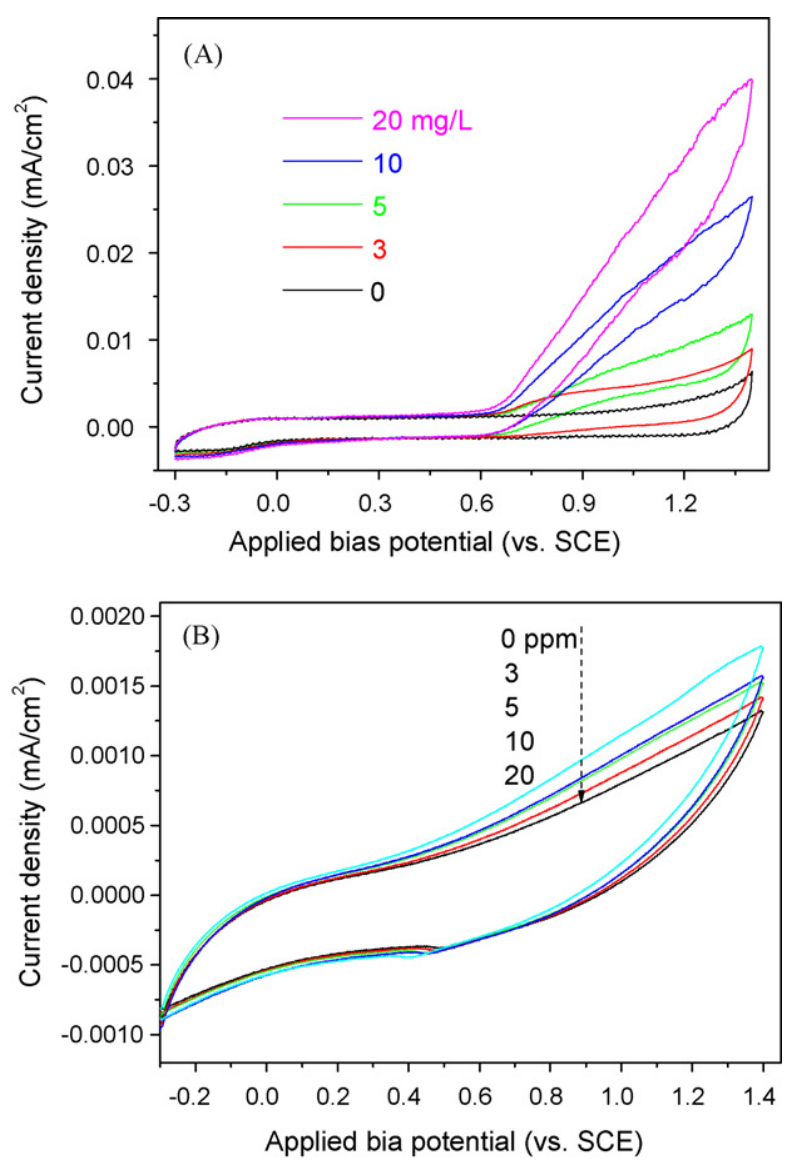

Fig. 1. Cyclic voltammograms of diclofenac with various concentrations at BDD electrode (A) and glass carbon electrode (B) ( $0.1 \mathrm{M} \mathrm{Na}_{2} \mathrm{SO}_{4}$ electrolyte).

In the present work, electrochemical oxidation of diclofenac in aqueous solution at BDD electrode was investigated, which has not been reported previously. Degradation intermediates were identified and a possible degradation pathway was proposed. And, largely different effects of applied bias and the addition of $\mathrm{NaCl}$ on diclofenac degradation were observed and explored. Relatively high initial concentrations of diclofenac were tested in order to investigate the effectiveness of BDD electro-oxidation process in removing diclofenac in aqueous solutions and to assess the nature and toxic variation of the main intermediates along the mineralization route. This latter aspect is of particular relevance, since potentially toxic species may be produced by incomplete degradation of diclofenac and their assessment is important if the method should be applied for water treatment.

\section{Materials and methods}

Diclofenac was purchased from Sigma-Aldrich Chemie (Steinheim, Germany). Stock solutions of diclofenac were prepared with Milli-Q purified water (Millipore). All chemicals used were reagent grade. Highly BDD electrode used in this work were purchased by CSEM (Switzerland) and synthesized on single crystal p-type $\mathrm{Si}(100)$ wafers, with resistivity of $0.1 \Omega \mathrm{cm}$, by the hot filament chemical vapour deposition technique. It consists of a coating of nano-polycrystalline boron-doped diamond (BDD) film with the thickness of $2 \mu \mathrm{m}$ (Fig. S1).

Degradation experiments were performed in a rectangular $(50 \mathrm{~mm} \times 50 \mathrm{~mm} \times 100 \mathrm{~mm})$ reactor, which is made from quartz glass. The reactor contained a $100 \mathrm{~mL}$ reaction solution allowing $3.5 \mathrm{~cm}$ of the electrode to be immersed into the solution. The electrochemical reaction employed a basic electrochemical system (Princeton Applied Research) connected with a counterelectrode (Pt wire, $70 \mathrm{~mm}$ in length with a $0.4-\mathrm{mm}$ diameter), a working electrode (the BDD electrode, active area of $12 \mathrm{~cm}^{2}$ ), and a reference electrode (a saturated calomel electrode (SCE)). About $0.1 \mathrm{~mol} / \mathrm{L}(\mathrm{M}) \mathrm{Na}_{2} \mathrm{SO}_{4}$ aqueous solution was used as electrolyte solution.

Initial concentration of diclofenac solution was $30 \mathrm{mg} / \mathrm{L}$ and was analyzed by reversed-phase high performance liquid chromatogram (HPLC) with a Hitachi HPLC apparatus (Diode Array Detector L-2450, Column Oven L-2300, and Pump L-2130). The $\mathrm{pH}$ value was determined to be 8.5. Diclofenac was determined by isocratic elution with $50 \%$ aqueous buffer solution with $10 \mathrm{mM}$ ammonium formicate $/ 50 \%$ acetonitrile. The flow rate was $1.0 \mathrm{~mL} / \mathrm{min}$ and the detection wavelength was set at $280 \mathrm{~nm}$. The concentration of total organic carbon (TOC) was analyzed using a multi N/C 3000 TOC analyzer (Analyti Jena AG, Germany). Prior to injection into the TOC analyzer, the samples were filtrated with $0.45 \mu \mathrm{m}$ Millipore filter. All experiments were carried out at least in duplicate. The reported
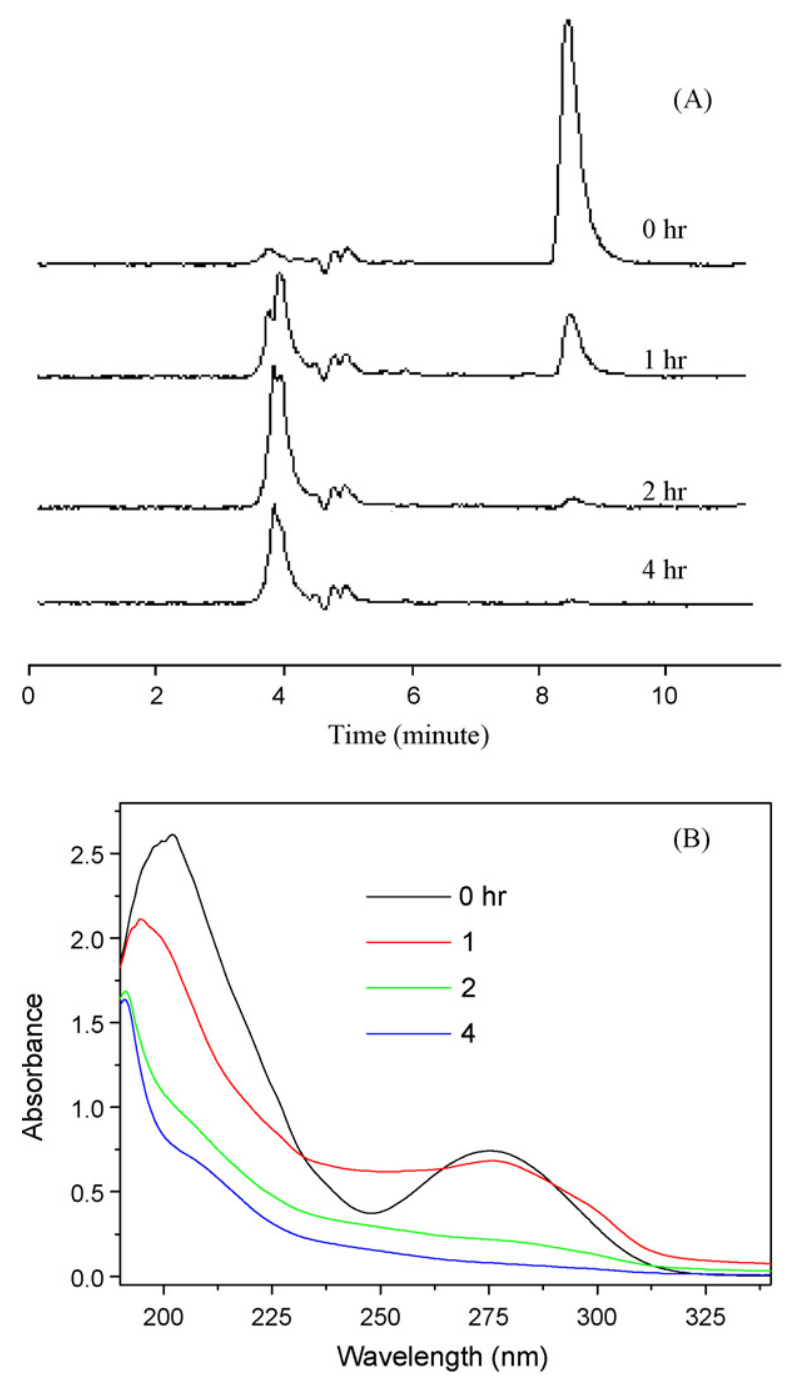

Fig. 2. Electro-oxidation of diclofenac at BDD electrode at various reaction times: (A) variation of HPLC spectra and (B) UV-vis spectra of diclofenac reaction solution (initial diclofenac concentration $30 \mathrm{mg} / \mathrm{L}$; applied bias potential, $4.0 \mathrm{~V} ; 0.1 \mathrm{M} \mathrm{Na}_{2} \mathrm{SO}_{4}$ electrolyte). 
Table 1

Potential intermediates identified in the electro-oxidation of diclofenac detected by GC-MS.

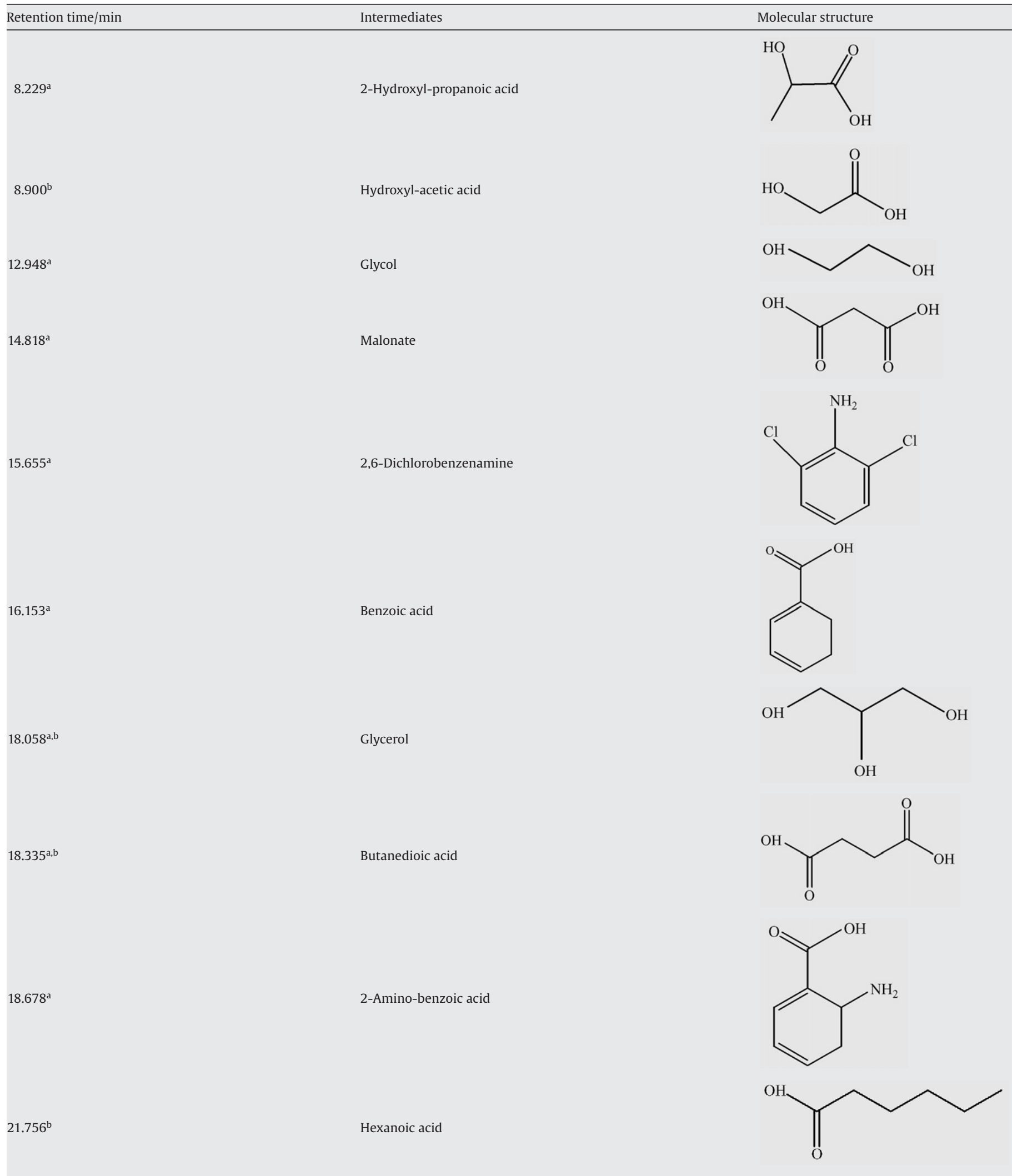




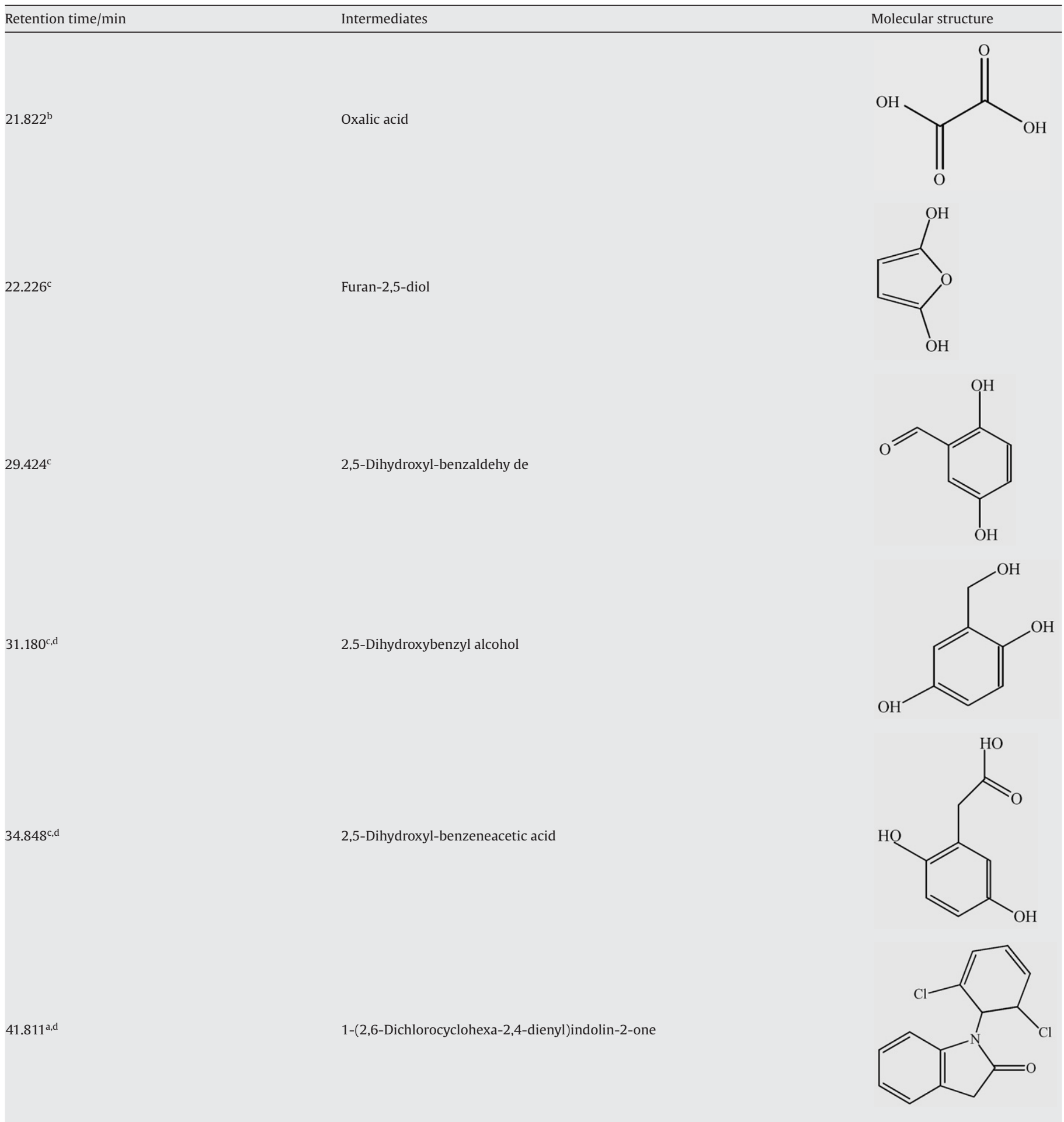

Reaction time: ${ }^{\mathrm{a}} 2 \mathrm{~h} ;{ }^{\mathrm{b}} 4 \mathrm{~h} ;{ }^{\mathrm{c}} 1 \mathrm{~h}$; ${ }^{\mathrm{d}} 0.5 \mathrm{~h}$ (30 mg/L diclofenac; $4.0 \mathrm{~V}$ applied bias potential; $0.1 \mathrm{M} \mathrm{Na}_{2} \mathrm{SO}_{4}$ electrolyte).

average values are within the experimental error of $\pm 3 \%$. For gas chromatography-mass spectroscopy (GC-MS) analysis, the residue was trimethylsilylated with $0.2 \mathrm{~mL}$ of anhydrous pyridine, $0.1 \mathrm{~mL}$ of hexamethyldisilazane, and $0.05 \mathrm{~mL}$ of chlorotrimethylsilane at room temperature. GC-MS analysis was carried out on an Agilent 6890GC/5973MSD with a DB-5 MS capillary column. Liquid chromatography/electrospray-time-of-flight mass spectrometry (LC/EIS-TOF-MS) with negative ionization was used to detect diclofenac chlorination products. Separation was not used. LC/TOF-MS accurate mass spectra were recorded from 50 to $1000 \mathrm{~m} / \mathrm{z}$.

The toxicity of an initial diclofenac solution and of aqueous samples collected at different reaction time was evaluated by monitoring changes in the natural emission of the luminescent bacteria Vibrio fischeri when challenged with toxic compounds. Briefly, samples were tested in medium containing $2 \%$ sodium chloride, in five dilutions and luminescence was recorded after 5 and $15 \mathrm{~min}$ of incubation at $15^{\circ} \mathrm{C}$. The inhibition of the luminescence, compared 


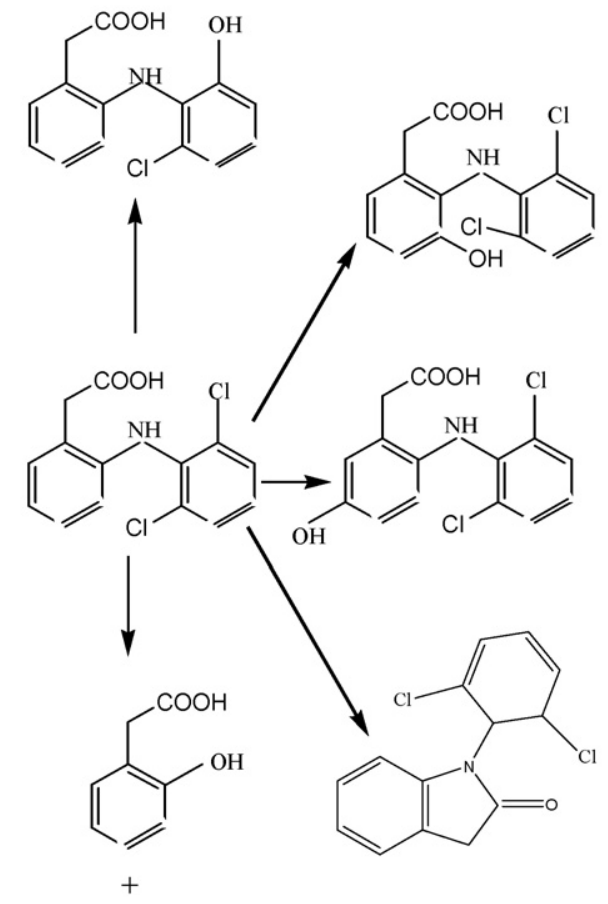<smiles>Nc1c(Cl)cccc1Cl</smiles><smiles>NC1=C(C(=O)O)C=CCC1C(=O)O</smiles><smiles></smiles>

$\mathrm{H}_{2} \mathrm{O}$

Scheme 1. Proposed electro-oxidation degradation pathway of diclofenac (initial concentration $30 \mathrm{mg} / \mathrm{L} ;$ applied bias potential, $4.0 \mathrm{~V}$; $0.1 \mathrm{M} \mathrm{Na}_{2} \mathrm{SO}_{4}$ ).

with a toxic-free control to give the percentage of inhibition, was calculated following the established protocol.

\section{Results and discussion}

\subsection{Voltammetric study}

Cyclic voltammogram of diclofenac solutions containing $0.1 \mathrm{M}$ $\mathrm{Na}_{2} \mathrm{SO}_{4}$ with BDD electrodes are shown in Fig. 1(A). At the potential higher than $0.75 \mathrm{~V}$ vs. SCE, the current densities increase with the concentration of diclofenac. The increased current densities may result from the direct electro-oxidation of diclofenac at BDD electrode. When the potential exceeds $1.3 \mathrm{~V}$, the anodic currents increased largely with the potential, which may result from electrooxidation of diclofenac plus the evolution of oxygen. With the evolution of oxygen, the active species such as hydroxyl radicals, $\mathrm{H}_{2} \mathrm{O}_{2}$, or $\mathrm{O}_{3}$ can be produced, which lead to the indirect oxidation of diclofenac. CV curves for diclofenac at a glassy carbon were also examined and shown in Fig. 1(B). It can be seen that the current increase with the increase of diclofenac concentration since the potential of $0.4 \mathrm{~V}$ (vs. SCE). In comparison with the $\mathrm{CV}$ results at BDD electrode, the increase of current is less. These results indicate that the high electrocatalytic activities of BDD electrode. Additionally, the effect of $\mathrm{NaCl}$ on the voltammetric experiments of diclofenac and comparison of different $\mathrm{CV}$ behaviors in $\mathrm{Na}_{2} \mathrm{SO}_{4}$ and $\mathrm{NaCl}$ will be described in another work.

\subsection{Degradation of diclofenac}

The initial concentration of diclofenac was $30 \mathrm{mg} / \mathrm{L}$. At the reaction time of $0.5,1,2,3$, and $4 \mathrm{~h}$, the concentration of diclofenac was reduced to $18.3,10.6,5.1,1.9$, and $1.1 \mathrm{mg} / \mathrm{L}$. Nearly complete abatement of diclofenac is observed within $4 \mathrm{~h}$. And, $72 \%$ diclofenac is mineralized within $4 \mathrm{~h}$ based on the TOC analysis. It can be seen from Fig. 2(A) that some near peaks appear with the decrease of diclofenac concentration. And the intensity of new peaks decreases with the extension of reaction time. These results suggested that the intermediates were produced at the initial reaction time, which were degraded with the extension of reaction process. As shown in Fig. 2(B), the decrease in UV-vis absorbance of the reaction solution furthermore confirms the above conclusion. 


\subsection{Identification of intermediates and proposed degradation pathways}

The main intermediates of diclofenac generated during the BDD electro-oxidation process were identified by GC-MS with library spectra (Table 1). It is observed that 2,6-dichlorobenzenamine and benzoic acid are identified at the reaction time of $2 \mathrm{~h}$. 1-(2,6-Dichlorocyclohexa-2,4-dienyl)indolin-2-one are also identified. These intermediates disappear at the reaction time of $4 \mathrm{~h}$. Many small molecular acids such as hydroxyl-acetic acid, 2-hydroxyl-propanoic acid, malonate, butanedioic acid, hexanoic acid, and oxalic acid are identified. Based on these results, it can be concluded that diclofenac was degraded by cleavage of $\mathrm{C}-\mathrm{N}$ bond firstly. And, some aromatic compounds are formed, which are degraded by ring open way. Finally, some small molecular acids are produced. A proposed electro-oxidation pathway of diclofenac with the applied bias potential of $4.0 \mathrm{~V}$ was given in Scheme 1. At the same time, the degradation intermediates of diclofenac with the $2.5 \mathrm{~V}$ applied bias potential at $4 \mathrm{~h}$ was also identified. Similar aromatic compounds and small molecular acids are also identified, which indicated that the reaction pathways of diclofenac at 4.0 and $2.5 \mathrm{~V}$ are similar.

\subsection{Effect of applied bias potential}

Furthermore, the effect of applied bias potential on diclofenac degradation was investigated. Fig. 3 shows the electrochemical degradation of diclofenac at various applied bias potentials ranging from 0.8 to $4.0 \mathrm{~V}$. Degradation of diclofenac is observed at all applied bias potentials; the degradation rate increases with the increasing bias potential. Two possible mechanisms were taken into account to explain the degradation behavior of diclofenac (Fig. 3(A)), involving direct oxidation and indirect oxidation mediated by reactive oxidants (ROs) generated during the electrolysis of $\mathrm{H}_{2} \mathrm{O}$ [23-25]. At the meantime, diclofenac concentration vs. volume-normalized charge quantity was presented in Fig. 3(B). It can be seen that the specific charge consumed for diclofenac degradation increases with increasing applied bias potential, which means that increasing applied bias potential causes acceleration of $\mathrm{O}_{2}$ evolution reaction, which will consume charge quantity.

No remarkable degradation of diclofenac was achieved at anodic potential below $1.2 \mathrm{~V}$, for which $\mathrm{H}_{2} \mathrm{O}$ electrolysis nearly cannot occur, which indicated that the contribution of direct oxidation is not significant. The other possible mechanism responsible for the diclofenac degradation is indirect oxidation mediated by several oxidants produced from the oxidation of water. ROs such as $\bullet \mathrm{OH}, \mathrm{O}_{3}, \mathrm{H}_{2} \mathrm{O}_{2}$, and $\bullet^{\bullet} \mathrm{O}_{2}{ }^{-}$can be considered as candidate oxidants [26]. The most common oxidation is the $\bullet \mathrm{OH}$ radicals formed by the one-electron oxidation of water. Additionally, other ROs can also be responsible for the diclofenac degradation. As shown in Fig. S2, the impedance spectra with the bias potential of $1.3 \mathrm{~V}$ is different from that with the potential of 2.5 and $4.0 \mathrm{~V}$, which indicates that the degradation mechanism of diclofenac at $1.3 \mathrm{~V}$ may be different from that at 2.5 and $4.0 \mathrm{~V}[27,28]$. Fig. 4 presents Bode phase plots in the blank $\mathrm{NaCl}$ electrolyte and in a $30 \mathrm{mg} / \mathrm{L}$ diclofenac solution at a current potential of $2.5 \mathrm{~V}$. Each peak in the Bode phase plot corresponds to a reaction that affects the impedance to current flow. The first peak centered near $1000 \mathrm{~Hz}$ in the blank electrolyte corresponding to $\mathrm{H}_{2} \mathrm{O}$ oxidation [29]. In the diclofenac solutions, several unresolved peaks centered near 1 and $100 \mathrm{~Hz}$ are observed which are the reaction results involving electrochemical oxidation of diclofenac and its reaction products. The chronoamperometry results (Fig. 5) have shown that the BDD electrode is rapidly deactivated during anodic polarization in the potential of $0.9 \mathrm{~V}$, which may be attributed to electrode fouling by polymeric products. However, in the potential region of water electrolysis, diclofenac oxidation
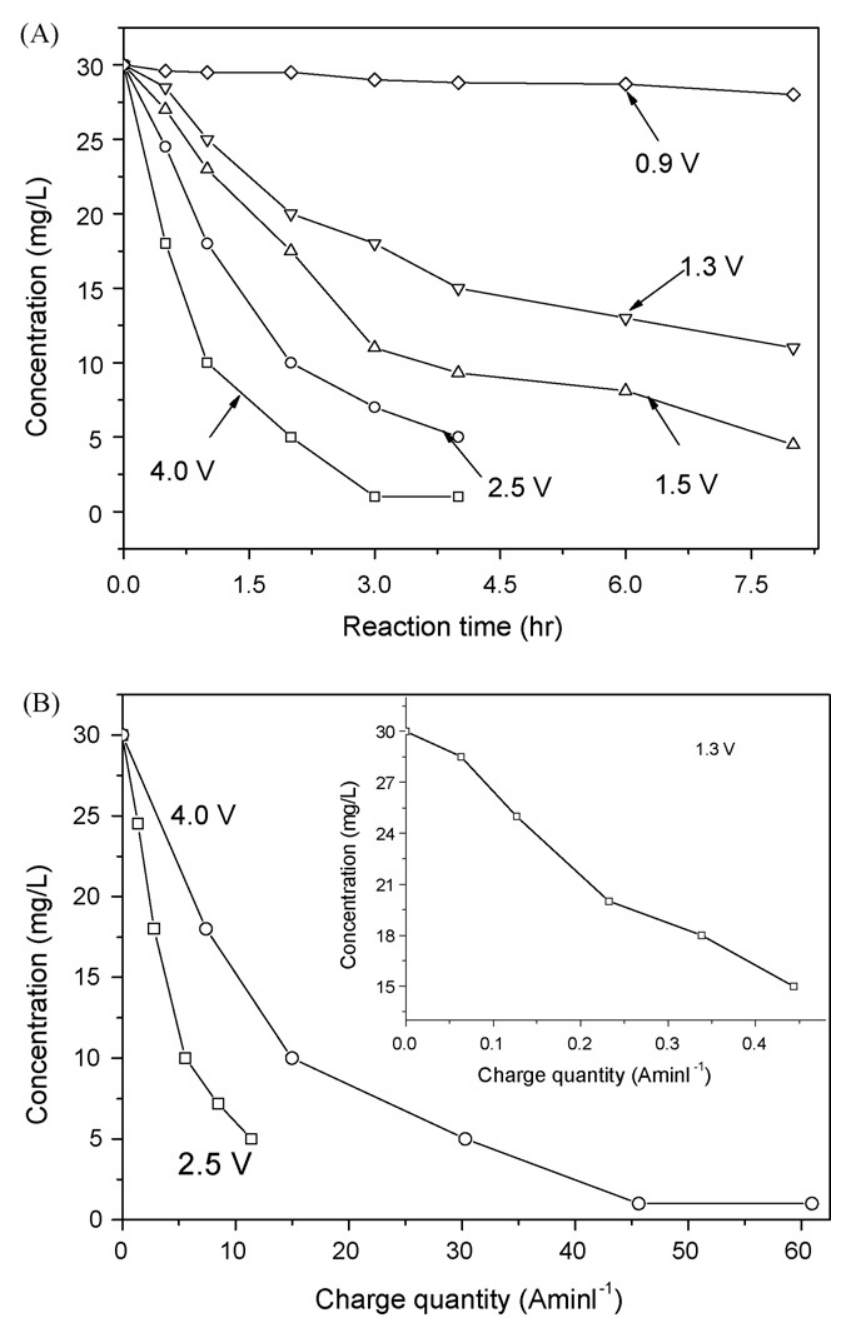

Fig. 3. Electro-oxidation of diclofenac at BDD electrode at various reaction times: (A) effect of applied bias potential and (B) effect of charge quantity on diclofenac degradation (initial diclofenac concentration, $30 \mathrm{mg} / \mathrm{L} ; 0.1 \mathrm{M} \mathrm{Na}_{2} \mathrm{SO}_{4}$ electrolyte).

involves active intermediates that can avoid electrode deactivation. In this region, the amount of electrogenerated ROs and the nature of oxidation products can be controlled by a proper choice of the applied current density. In particular, at low current density and high diclofenac concentration, low diclofenac conversion are

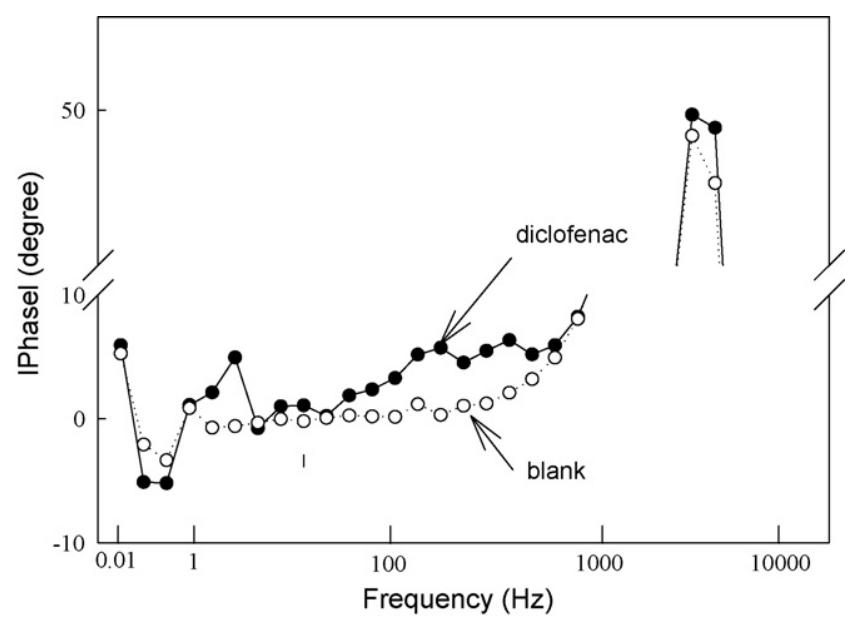

Fig. 4. Bode phase plots in $0.1 \mathrm{M} \mathrm{NaCl}$ electrolyte in the presence and absence of diclofenac at a bias potential of $2.5 \mathrm{~V}$. 

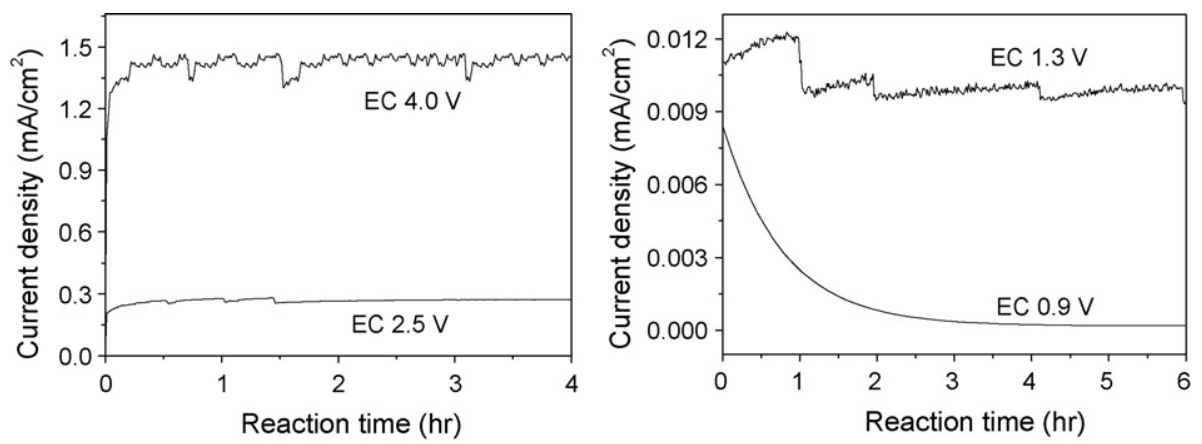

Fig. 5. Potentiostatic $I-t$ curves in a stirred reaction solution recorded at several applied potential (initial diclofenac concentration, $30 \mathrm{mg} / \mathrm{L} ; 0.1 \mathrm{M} \mathrm{Na} 2 \mathrm{SO}_{4}$ electrolyte).

formed; while at high current density and low diclofenac concentration, most of diclofenac are mineralized into $\mathrm{CO}_{2}$.

\subsection{Effect of $\mathrm{NaCl}$ on diclofenac degradation kinetics and pathway}

It can be seen from Fig. 6 that the addition of $\mathrm{Cl}^{-}$slows down the degradation rate of diclofenac and TOC removal rate. Because the potential of $\mathrm{Cl}_{2}$ evolution is below than that of $\mathrm{O}_{2}$ evolution, $\mathrm{Cl}_{2}$ evolution will lead to the decrease rate of $\mathrm{H}_{2} \mathrm{O}$ electrolysis. As a result, the amount of $\bullet \mathrm{OH}$ generated from $\mathrm{H}_{2} \mathrm{O}$ electrolysis is reduced. Thus, the rates of diclofenac degradation and TOC removal will be decreased.

As shown in Fig. 7(A) and (B), HPLC and UV-vis spectra variation with the reaction time in the diclofenac electro-oxidation in $\mathrm{NaCl}$ solution is different from that in $\mathrm{Na}_{2} \mathrm{SO}_{4}$ solution (Fig. 2(A) and (B)), which indicate that some different intermediates may be produced. It is known that electrochemical oxidation of $\mathrm{Cl}^{-}$produces hypochlorous acid $(\mathrm{HOCl})$ or the hypochloride ion $\left(\mathrm{OCl}^{-}\right)$depending on the solution $\mathrm{pH} . \mathrm{Cl}_{2}$ is the main chlorine species at $\mathrm{pH}<3 ; \mathrm{HOCl}$ in the region $3 \leq \mathrm{pH} \leq 7$, and $\mathrm{OCl}^{-}$at $\mathrm{pH}>7$ [30]. The $\mathrm{pH}$ value of the initial diclofenac solution was determined to be 6.7. Thus, $\mathrm{HOCl}$ can be produced. And, some undesirable organic chloride compounds may be formed. Dichlorodiclofenac was identified using TOF-MS analytic method. The analytic results of TOF-MS were shown in Fig. S3. The results were consistent with that reported by Miyamoto et al. [31]. These chlorinated intermediates may be responsible for the slow TOC removal rate as shown in Fig. 6. Although available analytical information does not allow the precise position of the $\mathrm{HOCl}$ attack to be predicted, considerations concerning the reactivity of the different sites on the diclofenac molecule [21] suggest chlorination of $\mathrm{C}-5$, which is para to the $\mathrm{NH}$ substitute as the

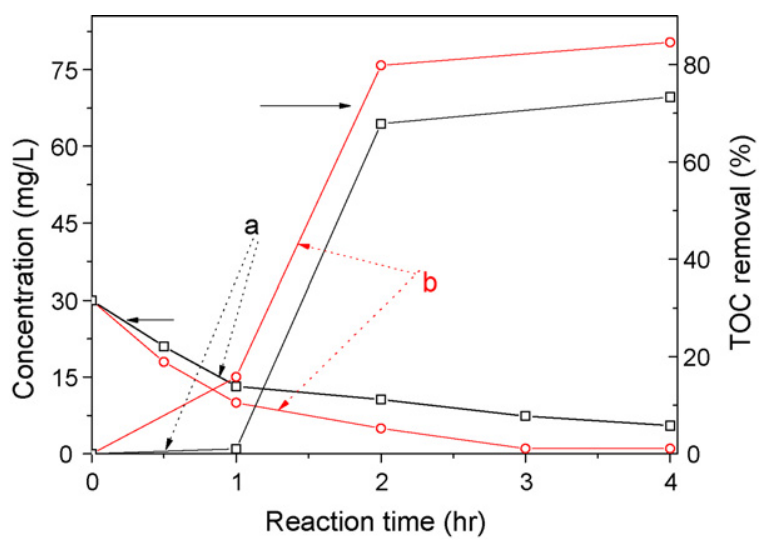

Fig. 6. Variation of diclofenac concentration and TOC in electro-oxidation process in the presence of $0.1 \mathrm{M} \mathrm{NaCl}$ (a) and $\mathrm{Na}_{2} \mathrm{SO}_{4}$ (b) (initial diclofenac concentration, $30 \mathrm{mg} / \mathrm{L}$; applied bias potential, $4.0 \mathrm{~V})$. most probable option on the basis of their electrophilic character and frontier electron densities (FED) theory. This hypothesis is consistent with previous publications [31]. Subsequently, these chlorination intermediates were degraded, which was supported by the GC-MS analysis.
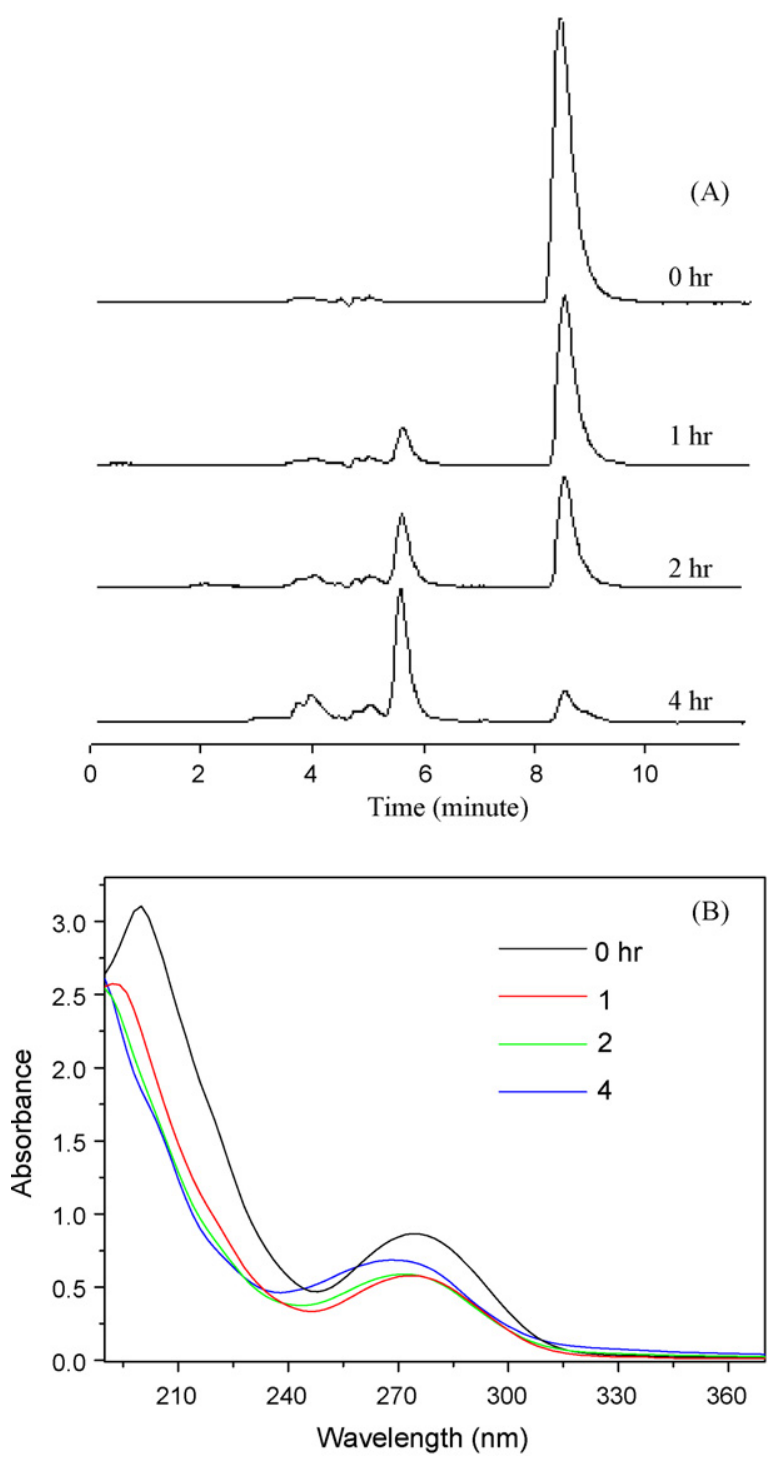

Fig. 7. Electro-oxidation of diclofenac at BDD electrode at various reaction times: (A) variation of HPLC spectra and (B) UV-vis spectra of diclofenac electro-oxidation process (initial diclofenac concentration, $30 \mathrm{mg} / \mathrm{L}$; applied bias potential, $4.0 \mathrm{~V} ; 0.1 \mathrm{M}$ $\mathrm{NaCl}$ electrolyte). 
During the electro-oxidation process in $\mathrm{Na}_{2} \mathrm{SO}_{4}$ electrolyte, the generation of intermediates increases until a maximum concentration is reached. Subsequently, these intermediates are degraded. It can be related to the toxicity results. The toxicity of the solution at different reaction time at $4.0 \mathrm{~V}$ was measured. The inhibition rate was $65,89,76$, and $23 \%$ corresponding to the reaction time of $0,2,4$, and $12 \mathrm{~h}$. The increase in the inhibition of the bacteria test goes with the increase in toxic intermediates. A maximum value of inhibition percentage is observed at $2 \mathrm{~h}$. After that, a decrease appears due to the diminishing concentration of toxic intermediates. Even if a correlation between the intermediates formed and the toxicity can be seen, it has not been possible to assess which molecule is responsible for the toxicity. These observations clearly demonstrate that transformation intermediates are more toxic than single diclofenac at the initial reaction period. When the reaction time was extended to $12 \mathrm{~h}$, the inhibition was $23 \%$, which indicated that BDD electrooxidation is efficient in reducing the toxicity of diclofenac aqueous solution.

\section{Conclusions}

It has been exhibited that the electro-oxidation using BDD electrode is effective in inducing diclofenac degradation. The diclofenac degradation was found to follow the reaction pathways leading to hydroxylated intermediates and $\mathrm{C}-\mathrm{N}$ cleavage intermediates through competitive routes. Subsequent oxidative ring cleavage leads to carboxylic acid fragments. At the low applied bias potential, direct electro-oxidation of diclofenac did not occur although there was anode oxidation peak in the CV curve. Electro-oxidation degradation of diclofenac is mainly performed by the active radicals produced in the anode electro-oxidation process with the application of high bias potential. Addition of $\mathrm{NaCl}$ into the diclofenac reaction solution decreases the TOC removal rate at the reaction initial period. And, some chlorination products were identified. Inhibition of the bacteria increased with the reaction time at the initial reaction phase and gradually decreased with the extension of reaction time. Transformation intermediates at the initial reaction period were more toxic than single diclofenac.

\section{Acknowledgements}

This work was supported by the Funds for Creative Research Groups of PR China (No. 50621804) and the National Natural Science Foundation of China (Nos. 20837001, 50538090, and 50778172). This research was also supported by the Knowledge Innovation Pro- gram of the Chinese Academy of Sciences (RCEES-QN-2007Z007) and the Special Funds for Young Scholars of RCEES, CAS.

\section{Appendix A. Supplementary data}

Supplementary data associated with this article can be found, in the online version, at doi:10.1016/j.electacta.2009.02.059.

\section{References}

[1] M. Carballa, F. Omil, J.M. Lema, M. Llompart, C. Garcia-Jares, I. Rodriguez, M. Gomez, T. Ternes, Water Res. 38 (2004) 2918.

[2] K.E. Conn, L.B. Barber, G.K. Brown, R.L. Siegrist, Environ. Sci. Technol. 40 (2006) 7358.

[3] N.M. Vieno, H. Harkki, T. Tuhkanen, L. Kronberg, Environ. Sci. Technol. 41 (2007) 5077.

[4] C. Zwiener, F.H. Frimmel, Water Res. 34 (2000) 1881.

[5] K. Kimura, H. Hara, Y. Watanabe, Environ. Sci. Technol. 41 (2007) 3708.

[6] M.M. Huber, S. Canonica, G.Y. Park, U. von Gunten, Environ. Sci. Technol. 37 (2003) 1016.

[7] J. Hartmann, P. Bartels, U. Mau, M. Witter, W.V. Tumpling, J. Hofmann, E. Nietzschmann, Chemosphere 70 (2008) 453.

[8] J. Hofmann, U. Freier, M. Wecks, S. Hohmann, Appl. Catal. B: Environ. 70 (2007) 447.

[9] P. Calza, V.A. Sakkas, C. Medana, C. Baiocchi, A. Dimou, E. Pelizzetti, T. Albanis, Appl. Catal. B: Environ. 67 (2006) 197.

[10] F. Méndez-Arriaga, R.A. Torres-Palma, C. Petrier, S. Esplugas, J. Gimenez, C. Pulgarin, Water Res. 42 (2008) 4243-4248.

[11] S. Encinas, F. Bosca, M.A. Miranda, Chem. Res. Toxicol. 11 (1998) 946.

[12] X. Chen, G. Chen, P.L. Yue, Chem. Eng. Sci. 58 (2003) 995.

[13] X. Chen, G. Chen, F. Gao, P.L. Yue, Environ. Sci. Technol. 37 (2003) 5021.

[14] N. Bensalah, A. Gadri, P. Canizares, C. Saez, J. Lobato, M.A. Rodrigo, Environ. Sci. Technol. 39 (2005) 7234.

[15] J. Iniesta, P.A. Michaud, M. Panizza, G. Cerisola, A. Aldaz, C. Comninellis, Electrochim. Acta 46 (2001) 3573.

[16] F. Montilla, P.A. Michaud, E. Morallon, J.L. Vazquez, C. Comninellis, Electrochim. Acta 47 (2002) 3509.

[17] N. Lindqvist, T. Tuhkanen, L. Kronberg, Water Res. 39 (2005) 2219.

[18] H.R. Buser, T. Poiger, M.D. Muller, Environ. Sci. Technol. 32 (1998) 3449.

[19] A. Tauxe-Wuersch, L.F. De Alencastro, D. Grandjean, J. Tarradellas, Water Res. 39 (2005) 1761.

[20] M. Cleuvers, Ecotoxicol. Environ. Safe. 59 (2004) 309.

[21] D. Vogna, R. Marotta, A. Napolitano, R. Andreozzi, M. d'Ischia, Water Res. 38 (2004) 414.

[22] M. Ravina, L. Campanella, J. Kiwi, Water Res. 36 (2002) 3553.

[23] J. Jeong, J.Y. Kim, J. Yoon, Environ. Sci. Technol. 40 (2006) 6117.

[24] A.N. Alshawabkeh, H. Sarahney, Environ. Sci. Technol. 39 (2005) 5837.

[25] L. Codognoto, S.A.S. Machado, L.A. Avaca, J. Appl. Electrochem. 33 (2003) 951.

[26] P.A. Michaud, M. Panizza, L. Ouattara, T. Diaco, G. Foti, C. Comninellis, J. Appl. Electrochem. 33 (2003) 151

[27] H. Liu, S. Cheng, M. Wu, H. Wu, J. Zhang, W. Li, C. Cao, J. Phys. Chem. A 104 (2000) 7016.

[28] X. Zhao, Y. Zhu, Environ. Sci. Technol. 40 (2006) 3367.

[29] J. Wang, J. Farrell, Environ. Sci. Technol. 38 (2004) 5232.

[30] C. Barrera-Diaz, G. Roa-Morales, L. Avila-Cordoba, T. Pavon-Silva, B. Bilyeu, Ind. Eng. Chem. Res. 45 (2006) 34.

[31] G. Miyamoto, N. Zahid, J.P. Uetrecht, Chem. Res. Toxicol. 10 (1997) 414. 